\title{
Opinión de la población migrante sobre los cuidados del equipo de salud en dos policlínicas municipales de Montevideo
}

\section{Migrant population's opinion on the healthcare team regarding patient care in two local outpatient clinics in Montevideo}

\section{Opinião da população migrante no cuidado da equipe de saúde em duas policínicas da prefeitura de Montevideu}

\author{
Alexis Barboza ${ }^{1}$, ORCID 0000-0003-4304-4807 \\ Daniela Casavieja ${ }^{2}$, ORCID 0000-0001-9400-5256 \\ Silvana López ${ }^{3}$, ORCID 0000-0002-9510-8430 \\ Katia Marina ${ }^{4}$, ORCID 0000-0002-8513-4221 \\ Nicolás Toledo ${ }^{5}$, ORCID 0000-0002-7195-6558 \\ 12345 Facultad de Enfermería, Universidad de la República. Uruguay
}

Recibido: 10/07/2019

Aceptado: 03/03/2020

Resumen: La presente investigación procura identificar la opinión de la población migrante sobre cuidados que faciliten su accesibilidad a los servicios de salud pública. La población objetivo comprende a migrantes internacionales que se atienden en dos policlínicas municipales de Montevideo, Uruguay. La investigación es de tipo cuantitativo, descriptiva y de corte transversal. La recolección de datos se realizó mediante encuesta, aplicada a 38 usuarios migrantes mayores de 18 años, con un mínimo de tres consultas realizadas en las policlínicas seleccionadas. El perfil socio demográfico demostró un predominio del rango etario comprendido entre 28 y 38 años $(47,4 \%)$, de género femenino $(68,4 \%)$, procedente de países de América Latina y del Caribe $(98,4 \%)$ y con un nivel de instrucción universitario $(63,8 \%)$. En cuanto a cuidados, el $92,1 \%$ de los encuestados refirió sentir buena recepción en las policlínicas y el 100\% manifestó desear seguir con su atención. Los cuidados valorados como más facilitadores en la accesibilidad fueron los relacionados con la comunicación $(97,4 \%)$ y la calidad del asesoramiento $(89,5 \%)$. El cuidado cultural definido por el interés del Equipo de Salud por la cultura y creencias- resultó ser el menos preponderante, con el $41,2 \%$ y $62,5 \%$ de respuestas negativas respectivamente.

Palabras claves: cuidados; accesibilidad a los servicios de salud; migrante; Enfermería Transcultural

Abstract: This research aims to identify the opinion of the migrant population regarding patient care that eases their access to Public Healthcare Services. The target population is international migrants who attend two local outpatient clinics in Montevideo, Uruguay. The research is quantitative, descriptive and crosssectional. Data collection was carried out through a survey, applied to 38 migrant users who were over 18 years old, with a minimum of three consultations carried out at the selected outpatient clinics. The socio- 
demographic profile showed a predominance of the age range between 28 and 38 years old (47.4\%), the female gender (68.4\%), countries from Latin America and the Caribbean (98.4\%) and a higher education level (63.8\%). Regarding patient care, $92.1 \%$ of respondents reported feeling the attention was suitable at the outpatient clinics and $100 \%$ stated they desired to continue attending. The most helpful types of patient care regarding access improvements were those related to communication (97.4\%) and the quality of advisory services (89.5\%). Cultural care - defined as the Healthcare Team's interest in the patient's culture and beliefs- proved to be the least prevalent with $41.2 \%$ and $62.5 \%$ negative responses, respectively.

.Keywords: care; accessibility to health services; migrant; Cross-cultural Nursing

Resumo: Esta pesquisa procura identificar a opinião da população migrante sobre os cuidados que facilitam sua acessibilidade aos serviços públicos de saúde. A população-alvo inclui migrantes internacionais afiliados e atendidos em duas policlínicas da prefeitura de Montevidéu, Uruguai. A pesquisa é quantitativa, descritiva e transversal. A coleta de dados foi realizada por meio de uma pesquisa, aplicada à 38 usuários migrantes acima de 18 anos, com um mínimo de três consultas realizadas nas policlínicas selecionadas. $\mathrm{O}$ perfil sociodemográfico mostrou predominância da faixa etária entre 28 e 38 anos (47,4\%), do sexo feminino $(68,4 \%)$, dos países da América Latina e do Caribe $(98,4 \%)$ e com nível de ensino universitário $(63,8 \%)$. Em relação aos cuidados, $92,1 \%$ dos entrevistados relataram sentir-se bem recebidos nas policlínicas e $100 \%$ afirmaram querer continuar com a atenção. Os cuidados avaliados como os mais facilitadores em acessibilidade foram os relacionados à comunicação $(97,4 \%)$ e à qualidade do aconselhamento (89,5\%). O cuidado cultural - definido pelo interesse da equipe de saúde em cultura e crenças - mostrou-se o menos prevalente, com $41,2 \%$ e $62,5 \%$ de respostas negativas, respectivamente.

Palavras-chave: assistência; acessibilidade aos serviços de saúde; migrante; Enfermagem Intercultural

Correspondencia: Katia Marina, e-mail: katiamarina.com@gmail.com

\section{Introducción}

Más de treinta millones de personas se han movilizado dentro y fuera de América Latina y el Caribe en las dos últimas décadas. Se asiste desde 2009 a un aumento y diversificación del flujo migratorio hacia Uruguay, tendencia que se confirmó a partir de 2014 y hasta la actualidad (1). Estadísticas del Ministerio de Relaciones Exteriores indican que para el año 2014, 730 personas de países del Mercosur o asociados iniciaron su trámite de residencia. En 2018, esta cifra se elevó a 10861 personas. (2) La Dirección Nacional de Migraciones (DNM) indica que en 2017, 3667 nacionales de países no pertenecientes al Mercosur ni Estados asociados iniciaron su trámite de residencia (3), mientras que en 2019 lo hicieron 5788 individuos. (4) El Alto Comisionado de las Naciones Unidas para los Refugiados (ACNUR) anuncia 6425 solicitantes de asilo para el año 2018 y 391 refugiados, lo que lleva la cifra de personas vinculadas con el refugio a un total de 6816. (5) 
Entre los países solicitantes, predominan los denominados "nuevos orígenes latinoamericanos", que incluyen países de Latinoamérica y del Caribe (1). Para los Estados Mercosur y asociados prevalece Venezuela con 5448 residencias tramitadas en 2018, seguida por Brasil (1880) y Argentina (1484). (2) De los países extra Mercosur se destaca Cuba: 968 cubanos iniciaron su trámite de residencia en 2017 (3), mientras que 4128 lo hicieron en 2019. (4) No se encontraron datos oficiales de ACNUR que indicaran cifras del refugio discriminados por nacionalidad.

La Ley de Migración uruguaya establece que "las personas migrantes y sus familiares gozarán de los derechos de salud, trabajo, seguridad social, vivienda y educación en un pie de igualdad con los nacionales" (6).

A su llegada, los migrantes internacionales no siempre poseen los documentos necesarios para iniciar el trámite de residencia y se enfrentan además a tiempos de espera mayores a seis meses para regularizar su situación.

La afiliación al sistema de salud pública requiere determinada documentación y es una condición excluyente para acceder a la integralidad de los servicios del Primer Nivel de Atención (PNA) (7). Por ende, aquellas personas sin posibilidad de afiliación sólo pueden atenderse en servicios de Emergencia o en consultas puntuales en el PNA, lo que dificulta la prevención y tratamiento de patologías crónicas u otras dolencias que no deberían ser atendidos en servicios de Emergencia. Por otra parte, una vez obtenida la documentación que los habilita a solicitar la atención en los servicios del PNA, se presenta la dificultad en lograr la accesibilidad a tales servicios, debido a barreras de índole cultural, lingüística, socioeconómica o administrativa.

Las dos policlínicas de Montevideo elegidas para la investigación, pertenecen al PNA público y cuentan con una alta concurrencia de migrantes internacionales (1) debido a su ubicación en barrios céntricos, donde reside habitualmente esta población.

Apostando a la rápida integración al sistema de salud y a la red de PNA de personas de culturas y trayectorias de vida diversas, se concibe la necesidad de adaptar los cuidados del equipo de salud al proceso de atención socio sanitaria que necesitan recibir. Por lo tanto, es de fundamental importancia la calidad del diálogo entre usuarios y profesionales. Éste permite brindar cuidados que facilitan la accesibilidad a los servicios pertinentes, mejoran la calidad de vida de los usuarios y contribuyen a evitar consultas indebidas en servicios de Emergencia. En este proceso de entendimiento mutuo, resulta esencial conocer las necesidades sentidas por la población objetivo y su opinión acerca de los cuidados que mejor contribuyen a la calidad de la atención.

\section{Metodología}

El tipo de estudio es cuantitativo, descriptivo y de corte transversal. La muestra consta de 38 individuos que concurrieron a dos policlínicas municipales de Montevideo, en el período del 21 de mayo al 15 de junio de 2018, según un tipo de muestreo por conveniencia. Los criterios de inclusión fueron la nacionalidad extranjera, un mínimo de tres consultas previas realizadas en las dos policlínicas y ser mayor a 18 años. Los criterios de exclusión fueron un déficit intelectual que impidiera la comunicación y/o comprensión de lo expuesto en el estudio y/o el dominio insuficiente del idioma español.

Para determinar el perfil sociodemográfico de la muestra se estudiaron siete variables simples: edad, género, nacionalidad, idioma dominante, nivel de instrucción y tiempo de estadía. Para definir su opinión sobre los cuidados recibidos se trabajaron cuatro variables simples 
(vivencia, comunicación, confianza y cuidados) y tres variables compuestas (asesoramiento, hábitos y cuidados culturales).

Los datos se recolectaron mediante encuesta y el instrumento constó de 18 de preguntas. Las variables simples se trataron en una sola pregunta, como en el caso del idioma dominante: ¿Cuál es el idioma que mejor habla y entiende? O de la vivencia ¿Cuándo concurre a la policlínica, se siente bien recibido por los integrantes del equipo de salud? En el caso de las variables compuestas se definieron dos dimensiones, tratadas mediante preguntas distintas. Para evaluar el asesoramiento, se consideró necesario valorar la utilidad de la información (¿Le es útil la información que le dan los profesionales durante la consulta?) y el tiempo dedicado (¿Considera que el tiempo para su atención durante la consulta es suficiente?).

Las preguntas se completaron luego de corroborar los criterios de inclusión y obtener la firma del consentimiento. Previo a la recolección de datos, se realizó una prueba piloto en una tercera policlínica y se modificó el instrumento en base al resultado.

\section{Consideraciones éticas}

Previo a la recolección de datos, se presentó la solicitud de autorización dirigida a las autoridades correspondientes y se realizó un encuentro con los coordinadores de sendas policlínicas, a los efectos de informarles de los objetivos y la planificación de la investigación. En el momento de la recolección de datos, se les presentó a los encuestados seleccionados una versión por escrito del cuestionario, así como el consentimiento informado a ser firmado, de acuerdo con el Decreto sobre Investigación en Seres Humanos y la Ley de Protección de Datos Personales.

\section{Resultados}

El rango etario predominante fue el comprendido entre 29 a 38 años $(47,4 \%)$, seguido por los rangos entre 18 a 28 años y 38 a 48 años con $21,1 \%$. El 10,5\% de los encuestados eran igual o mayores a 48 años. El 68,4\% se identificó como pertenecientes al género femenino y el 31,8\% al género masculino. Las nacionalidades prevalentes fueron las de países de América Latina y del Caribe, que alcanzaron el 94,8\%. El primer país de procedencia fue Venezuela con un 36,9\%, seguido por República Dominicana (18,2\%), Brasil y Cuba (10.5\%), Perú, (7,9\%) y Bolivia, Ecuador, Honduras y Puerto Rico (2,6\%). En cuanto a orígenes extra americanos, participaron $2,6 \%$ de usuarios procedentes de Nigeria y España.

El 88,8\% de los encuestados tenían el español como primer idioma. Se incluyeron a 10,5\% de lusófonos y a 2,6\% de angloparlantes, cuyo nivel de español era suficiente para entender y completar el cuestionario. La mayoría de los encuestados $(63,2 \%)$ presentaron un nivel de estudios universitario. E1 28,9\% refirió haber alcanzado el nivel secundario, el 5,3\% el primario y el 2,6\% presentó una formación terciaria no universitaria. Con respecto al tiempo de estadía, la mayoría $(52,8 \%)$ lleva más de tres años viviendo en el país. El 11,1\% refirió un tiempo de estadía de dos a tres años, el 19,4\% de uno a dos años y el 16,7\% menor a un año.

La mayoría de los participantes $(92,1 \%)$ refirió una vivencia positiva respecto a su experiencia en las policlínicas, valorada a través de la calidad de la recepción por parte del equipo de salud. El 7,9\% matizó esta afirmación (a veces).

La variable confianza fue evaluada a través de la oportunidad de poder expresar emociones, opiniones y sentimientos en las interacciones con el equipo. El 81,6\% de los encuestados afirmó 
poder hacerlo siempre, el $13,2 \%$ a veces y el 5,2\% no hacerlo nunca.

El 97,4\% de los encuestados confirmó la disposición sistemática de los profesionales para lograr una buena comunicación respecto a diagnósticos y planes de cuidados, mientras que el 2,6\% percibió dicha disposición como más esporádica.

El asesoramiento se analizó como una variable compuesta, contemplándose el tiempo dedicado a la consulta y la utilidad de la información brindada. El 81,6\% de los participantes consideró siempre suficiente el tiempo dedicado a sus consultas, el $13,2 \%$ a veces y el $5,2 \%$ insuficiente. La información brindada fue considerada útil por el $89,5 \%$ de los encuestados. El $7,9 \%$ refirieron utilidad esporádica, mientras que $6,2 \%$ no consideraron útil la información recibida. Combinando ambas dimensiones, el asesoramiento fue valorado por el 73,6\% de los encuestados como siempre adecuado. (Tabla 1)

Tabla 1 - Asesoramiento

\begin{tabular}{|c|c|c|c|c|c|}
\hline Asesoramiento & \multicolumn{5}{|c|}{ Utilidad de la información brindada } \\
\hline \multirow{5}{*}{$\begin{array}{l}\text { Tiempo de consulta } \\
\text { adecuado }\end{array}$} & & $\mathrm{Si}$ & No & A veces & Total \\
\hline & $\mathrm{Si}$ & $\begin{array}{l}28 \\
(73,6 \%)\end{array}$ & $0(0 \%)$ & $3(7,8 \%)$ & $31(81,5 \%)$ \\
\hline & No & $1(2,6 \%)$ & $1(2,6 \%)$ & $0(0 \%)$ & $2(5,2 \%)$ \\
\hline & A veces & $5(13,1 \%)$ & $0(0 \%)$ & $0(0 \%)$ & $5(13,1 \%)$ \\
\hline & Total & $\begin{array}{l}34 \\
(89,4 \%)\end{array}$ & $1(2,6 \%)$ & $3(7,8 \%)$ & $38(100 \%)$ \\
\hline
\end{tabular}

Fuente: Encuesta a migrantes internacionales/Elaboración propia. 2018.

La variable hábitos fue tratada como compuesta y valorada en función de dos dimensiones: el interés del equipo de salud en conocer hábitos de vida relevantes en el Proceso de Salud Enfermedad (PSE) y su disposición para elaborar planes de cuidados en consecuencia. El 57,9\% de los encuestados refirió que los integrantes del equipo indagaban sistemáticamente acerca de sus hábitos de vida, el 15,8\% de vez en cuando y el 26,3\% nunca. En cuanto a adaptar el plan de cuidados a los hábitos referidos, el 55,7\% de los profesionales trató de hacerlo siempre, el 39,5\% nunca y el 5,3\% a veces. Combinando ambas dimensiones, la variable hábitos fue sistemáticamente contemplada según el $44,7 \%$ de los encuestados.

El 97,4\% confirmó la disposición del equipo de salud por lograr una buena comunicación respecto a los diagnósticos y planes de cuidados planteados, así como por fundamentarlos en un lenguaje claro y entendible. (Tabla 2) 
Tabla 2 - Hábitos

\begin{tabular}{|c|c|c|c|c|c|}
\hline Hábitos & \multicolumn{5}{|c|}{ Interés en conocer los hábitos } \\
\hline \multirow{5}{*}{$\begin{array}{l}\text { Tener en } \\
\text { cuenta hábitos } \\
\text { en tratamiento } \\
\text { o plan de } \\
\text { cuidados. }\end{array}$} & & Sí & No & A veces & Total \\
\hline & Sí & $17(44,7 \%)$ & $4(10,5 \%)$ & $0(0 \%)$ & $21(55,2 \%)$ \\
\hline & No & $5(13,1 \%)$ & $6(17,7 \%)$ & $4(10,5 \%)$ & $15(39,4 \%)$ \\
\hline & A veces & $0(0 \%)$ & $0(0 \%)$ & $2(5,2 \%)$ & $2(5,2 \%)$ \\
\hline & Total & $22(57,8 \%$ & $10(26,3 \%)$ & $6(17,7 \%)$ & $38(100 \%)$ \\
\hline
\end{tabular}

Fuente: Encuesta a migrantes internacionales/Elaboración propia. 2018

Los cuidados culturales fueron valorados como una variable compuesta, a través del interés en conocer aspectos culturales, religiosos o espirituales que tuvieran relevancia en el PSE de los usuarios. La mayoría de los entrevistados $(65,8 \%)$ refirieron que el equipo de salud no realizó preguntas al respecto, mientras que el 31,6\% sí lo hizo. En cuanto a cultura, los resultados obtenidos demuestran mayor interés que por la dimensión religiosa, ya que los profesionales realizaron preguntas en forma sistemática $(42,1 \%)$ u ocasional $(15,8 \%)$. En su conjunto, el equipo de salud demostró interés sistemático por ambas dimensiones de los cuidados culturales según el $23,6 \%$ de los encuestados. (Tabla 3)

Tabla 3 - Cuidado cultural

\begin{tabular}{|c|c|c|c|c|c|}
\hline $\begin{array}{l}\text { Cuidado } \\
\text { cultural }\end{array}$ & \multicolumn{5}{|c|}{$\begin{array}{l}\text { Interés por conocer religión o creencias y su influencia en los hábitos } \\
\text { relacionados con la salud. }\end{array}$} \\
\hline \multirow{5}{*}{$\begin{array}{l}\text { Interés por } \\
\text { conocer aspectos } \\
\text { culturales que } \\
\text { influyen en la } \\
\text { forma de ver la } \\
\text { salud }\end{array}$} & & Sí & No & A veces & Total \\
\hline & Sí & $9(23,6 \%)$ & $7(18,4 \%)$ & $0(0 \%)$ & $16(42,1 \%)$ \\
\hline & No & $1(2,6 \%)$ & $15(39,5 \%)$ & $0(0 \%)$ & $16(42,1 \%)$ \\
\hline & A veces & $2(5,2 \%)$ & $3(7,8 \%)$ & $1(2,6 \%)$ & $6(15,8 \%)$ \\
\hline & Total & $12(31,6 \%)$ & $25(65,8 \%)$ & $1(2,6 \%)$ & $38(100 \%)$ \\
\hline
\end{tabular}

Fuente: Encuesta a migrantes internacionales/Elaboración propia. 2018.

Respecto a la variable cuidados, se desprende que la cuasi totalidad de los participantes $(94,7 \%)$ siempre consideró positiva su experiencia en la policlínica y el 5,3\% a veces. De hecho, el 100\% afirmó su deseo de seguir con su atención.

Los profesionales que demostraron mayor interés en establecer un vínculo terapéutico de calidad 
fueron la ginecóloga y la pediatra según el 30,8\% de los participantes. Siguen enfermería y partera $(11,5 \%)$, médico general, médico de familia, psicóloga y vacunadora $(3,8 \%)$.

\section{Discusión y Análisis}

El perfil sociodemográfico de la población encuestada corresponde con las tendencias estadísticas presentadas por un estudio de fuente estatal, que indica que la mayoría de las personas migrantes son adultos jóvenes, que acuden en búsqueda de oportunidades laborales. (1) A su vez, es relevante que el rango etario dominante contraste con el de la población uruguaya, en su mayoría conformada por adultos mayores, que acude a los centros asistenciales. (8)

El $68,4 \%$ de mujeres encuestadas confirma e incluso supera la tendencia presentada por fuentes oficiales para el periodo 2009-2014, que establece que el 54\% de la población migrante pertenece al género femenino (1). Coincide con la tendencia general de la población, según la cual las mujeres asisten mayoritariamente a los servicios de salud por consultas propias y por las de otros integrantes del núcleo familiar de los que asumen el cuidado. De hecho, la estadística nacional para el año 2018 indica que, a partir de los 15 años de edad, el número de usuarias mujeres supera el de los hombres en todas las etapas del ciclo vital (8).

En cuanto a la procedencia, las cifras obtenidas corresponden con las presentadas por el Estado para los denominados "orígenes latinoamericanos no tradicionales", que demuestran una marcada presencia de migrantes de Venezuela y de los países del Caribe (Cuba y República Dominicana). (1) Estas personas encuentran en Uruguay un país de fronteras abiertas, que hasta el momento no ha aplicado la deportación en ningún contexto y les permite acceder a los servicios de salud del primer nivel aún sin documentación nacional. Los migrantes procedentes de Venezuela, República Dominicana y Cuba comparten además varias características culturales con la población, que van desde el idioma y la religión hasta ciertos ritmos musicales y costumbres gastronómicas. (9)

La escasa procedencia extra americana puede deberse al criterio de inclusión del dominio del idioma español planteado por la investigación, que excluye a la mayoría de los usuarios africanos y de Medio Oriente. Respecto al predominio del español como idioma dominante, puede considerarse como un beneficio para la interrelación en los servicios de salud.

La mayoría de los encuestados $(63,2 \%)$ presentaron un nivel de estudios universitario, lo que concuerda con las estadísticas oficiales. (1) Dentro de los Determinantes sociales de la Salud, el nivel de instrucción integra el entorno en el cual se desarrollan individuos y familias e influye en su estilo de vida, hábitos, acceso a los servicios de salud y exposición a ambientes de riesgo. (10) A mayor nivel educativo, mayor acceso a los servicios sanitarios y mejor salud percibida a lo largo de la vida, debido a un mayor compromiso con el PSE. Por otro lado, las familias con mayor nivel educativo suelen presentar un menor número de hijos, lo que aumenta la capacidad de cuidado y protección de los padres sobre el núcleo familiar. (10) Finalmente, el nivel de formación de la madre es un factor que determina la salud, supervivencia y nivel educativo de los hijos. (12) Las personas auto identificadas con el género femenino que participaron en este estudio eran en su mayoría madres con un nivel educativo universitario. Esto constituye un indicador del alto nivel de participación de individuos -y en particular de mujeres y madres- en su PSE y en el de su núcleo familiar.

El tiempo de estadía en el país de la mayoría de los encuestados $(52,8 \%)$ era mayor a 3 años, lo cual indica que un mejor arraigo genera mayores probabilidades de disponer de toda la 
documentación que habilita y facilita la atención socio sanitaria. Por otro lado, demuestra que el tiempo es un factor determinante para la accesibilidad a los servicios de salud, ya que conlleva un mejor conocimiento del sistema sanitario, de sus prestadores, de sus profesionales y de su funcionamiento general.

La vivencia, relacionada con la recepción por parte de los integrantes del equipo de salud, fue valorada muy positivamente $(91,2 \%)$ y se asimila al porcentaje de satisfacción general respecto a la calidad de la atención recibida $(98,2 \%)$. El porcentaje de confianza referido por los encuestados revela que el $18,4 \%$ no siempre expresan sus emociones, opiniones y sentimientos en la consulta o no lo hacen nunca. Este resultado muestra la importancia de fortalecer la consulta como un espacio importante de intercambio y de libre expresión. Para ello, son fundamentales la empatía y las competencias culturales desarrolladas por los integrantes del equipo de salud.

La variable hábitos -definida como el conjunto de prácticas habituales de una persona o colectividad- fue evaluada a través del interés del equipo por las costumbres de vida y un tratamiento o plan de cuidados propuestos en función de las respuestas. La variable fue valorada sistemáticamente por el equipo según el $44,7 \%$ de los encuestados. Este porcentaje indica que los profesionales aún subestiman la importancia de un mejor conocimiento de los hábitos de poblaciones culturalmente diversas a la hora de establecer un plan de cuidados viable y coherente, que además genere un vínculo terapéutico basado en el compromiso.

Destacó la importancia relativa de los cuidados culturales en el abordaje terapéutico del equipo de salud. La mayoría de los participantes $(39,5 \%)$ refirió que éste no realizaba preguntas acerca de sus creencias religiosas ni aspectos culturales que pudieran influir en su forma de ver la salud. Sin embargo, los encuestados aclararon que no lo consideraban como una falta de interés por parte de los profesionales respecto a su PSE y que ello no perjudicaba la calidad de la atención recibida. Aun así, se observa que el enfoque integral y centrado en las personas todavía no ha sido plenamente incorporado al abordaje terapéutico. Si bien esto no afecta el desarrollo del proceso asistencial en sus aspectos prácticos como coordinación de estudios o prescripción de tratamientos, puede dar lugar a la formación de malentendidos y estereotipos. Además, el cuidado cultural se vuelve imprescindible cuando se atienden usuarios de culturas, idiomas y creencias muy diferentes, lo cual no es el caso en esta investigación. En un contexto de globalización, el equipo de salud debe adquirir las herramientas que le permitan abordar individuos y comunidades que requieran de la competencia cultural para elaborar planes de cuidados apropiados.

En cuanto a la valoración del cuidado brindado por los distintos integrantes del equipo de salud, cabe destacar el concepto positivo acerca de la ginecóloga y la pediatra, que identifica la importancia que reviste la salud de la mujer y del niño en una población joven en edad reproductiva.

En suma, la opinión general acerca de los cuidados recibidos resultó muy positiva y demostró la intención de la población encuestada de seguir concurriendo a las policlínicas. Éstas demostraron ofrecer los servicios adaptados a usuarios con el perfil socio demográfico de la población migrante caracterizada: predominio del sexo femenino y edad menor a cuarenta años.

La calidad de la comunicación y del asesoramiento fueron los cuidados mejor valorados y considerados como prioritarios para la accesibilidad a los servicios de salud. Las personas migrantes necesitan poder contar con el equipo de salud para facilitarles información relevante acerca de su proceso de atención, ya sea para acceder a los servicios en sí mismos o para garantizar su accesibilidad, vinculada con una buena comprensión de la información recibida. 
En el proceso asistencial de usuarios no hispanohablantes, el dominio de un idioma de interfaz constituye por lo tanto una herramienta esencial en el logro de la accesibilidad.

\section{Conclusiones}

El desarrollo de la investigación permitió en primer lugar cumplir con los objetivos propuestos: caracterizar a la población migrante de los centros asistenciales elegidos, definir su opinión sobre los cuidados recibidos e identificar cuáles considera como facilitadores en su accesibilidad a los servicios de salud. Aunque el tamaño relativamente reducido de la muestra insta a la cautela a la hora de extrapolar resultados, abre perspectivas alentadoras para futuras investigaciones. Pretende, además, poner de manifiesto el interés que los profesionales y prestadores de salud deben desarrollar por el Proceso Salud Enfermedad de la población migrante. $\mathrm{Su}$ perfil socio demográfico, epidemiológico y cultural requiere el desarrollo de conocimientos específicos por parte de los equipos interdisciplinarios, con el fin de mejorar la calidad de la atención y preservar la salud poblacional. El conocer la opinión de los propios usuarios acerca de los cuidados recibidos contribuye a mejorar la calidad de los mismos, sostener la continuidad de la atención y así asegurar la efectividad y eficiencia del proceso asistencial. En una sociedad cada vez más expuesta a nuevos aportes culturales, la incorporación oportuna de la población migrante al sistema nacional de salud es un desafío no sólo en términos de atención sanitaria, sino también de integración social.

\section{Referencias bibliográficas}

(1) República Oriental del Uruguay. Ministerio de Desarrollo Social. Caracterización de las nuevas corrientes migratorias en Uruguay: nuevos orígenes latinoamericanos: estudio de caso de las personas peruanas y dominicanas. [Internet]. 2017. [consulta: 29 ago 2017]. Disponible en: http://www.mides.gub.uy/innovaportal/file/75559/1/investigacion_caracterizacion2017_final _digital.pdf

(2) República Oriental del Uruguay. Ministerio de Relaciones Consulares. Dirección General para Asuntos Consulares y Vinculación. Informe anual 2018 Residencias permanentes de nacionales del Mercosur y familiares de uruguayos en el extranjero. Ley 19254. [Internet]. 2019. [consulta: $16 \quad 14$ abr 2020]. Disponible en: http://www.jnm.gub.uy/images/documentos/Informe_Residencias_2018_MRREE.pdf

(3) República Oriental del Uruguay. Dirección Nacional de Migraciones. Anuario 2017. [Internet]. 2018. [consulta: 14 abr 2020]. Disponible en: https://migracion.minterior.gub.uy/images/anuario17/09-RESIDENCIAS_2017.pdf

(4) República Oriental del Uruguay. Dirección Nacional de Migraciones. Anuario 2019. [Internet]. 2020. [consulta: 14 abr 2020]. Disponible en: https://migracion.minterior.gub.uy/images/anuario19/ANUARIO_2019.pdf

(5) Alto Comisionado de las Naciones Unidas para los Refugiados. Tendencias globales. Desplazamiento forzado en 2018. [Internet]. 2019 [consulta: 14 abr 2020]. Disponible en: https://acnur.org/5d09c37c4\#_ga=2.233805273.673666459.1582926104412249149.1577814855

(6) República Oriental del Uruguay. Migración. Ley No 18.250 de 17 enero de 2008. [Internet]. 2008 [consulta: 30 ago 2017]. Disponible en: 
https://www.oas.org/dil/esp/Ley_Migraciones_Uruguay.pdf

(7) Administración de los Servicios de Salud del Estado. Afiliación de extranjeros y retornados al país. [Internet]. 2018 [consulta: 03 may 2020]. Disponible en: http://afiliaciones.asse.com.uy/prestaciones_detail?id=P-5-extranjeros

(8) Administración de los Servicios de Salud del Estado. Datos de Usuarios: total del país de usuarios ASSE, por tipo de cobertura según sexo y grupos de edad. [Internet]. 2016 [consulta: 14 abr 2020]. Disponible en: file://C:/Users/Usuario/Downloads/2018_12_Diciembre.pdf

(9) Díaz CG. Tradiciones y costumbres caribeñas. [Internet]. 2012 [consulta: 10 jul 2018].

. Disponible en: https://enciclopediapr.org/encyclopedia/tradiciones-y-costumbres-caribenas/

(10) Organización Mundial de la Salud. Determinantes sociales de la salud: los hechos irrefutables. [Internet]. 2003 [consulta: 30 jul 2018]. Disponible en: https://escpromotorasdesalud.weebly.com/uploads/1/3/9/4/13940309/determinantes_sociales _de_la_salud._los_hechos_irrefutables.pdf

(11) Aguilar Palacio I., Carrera Las fuentes P., Rabanaque MJ. Salud percibida y nivel educativo en España: tendencias por comunidades autónomas y sexo (2001-2012). Gac Sanit [Internet]. 2015 [consulta: 10 jul 2018]; 29(1): 37-43. Disponible en: http://scielo.isciii.es/scielo.php?script=sci_arttext\&pid=S0213-91112015000100007

(12) Organización Mundial de la Salud. A conceptual framework for action on the social determinants of health. [Internet]. 2007[consulta: 10 jul 2018]. Disponible en: www.who.int/social_determinants/resources/csdh_framework_action_05_07.pdf

Cómo citar: Barboza, A., Casavieja, D., López, S., Marina, K., Toledo, N. Opinión de la población migrante sobre los cuidados del equipo de salud en dos policlínicas municipales de Montevideo. Enfermería: Cuidados Humanizados. 2020; 9(1): 44-53. Doi: https://doi.org/10.22235/ech.v9i1.2165

Contribución de los autores: a) Concepción y diseño del trabajo, b) Adquisición de datos, c) Análisis e interpretación de datos, d) Redacción del manuscrito, e) Revisión crítica del manuscrito. A.B. ha contribuido en a,b,c; D.C. en a,b,c; S.L. en a,b,c; K.M. en a,b,c,d,e; N.T. en a,b,c.

Editora científica responsable: Dra. Natalie Figueredo 